This is an accepted manuscript of an article published in The International Journal of Human Resource Management, April 2018 DOI: 10.1080/09585192.2018.1460859

Reimagining alienation within a relational framework: Evidence from the public sector in Ireland and the UK

\author{
Edel Conway* \\ DCU Business School \\ Dublin City University \\ Ireland \\ Email: edel.conway@dcu.ie \\ Kathy Monks \\ DCU Business School \\ Dublin City University \\ Ireland \\ Email: Kathy.monks@dcu.ie
}

$\mathrm{Na} \mathrm{Fu}$

Trinity Business School

Trinity College Dublin

Ireland

Email: funa@tcd.ie

Kerstin Alfes
ESCP Europe
Berlin
Germany

Email: kalfes@escpeurope.eu

Katie Bailey

Department of Business and Management

University of Sussex

Brighton

United Kingdom

Email: k.bailey@sussex.ac.uk

* Corresponding Author 


\title{
Reimagining alienation within a relational framework: Evidence from the public sector in Ireland and the UK
}

\begin{abstract}
This paper provides a counterbalance to the emphasis on positive psychology within recent HRM scholarship by utilizing a relational framework to explore the antecedents and outcomes of alienation. We focus on the associations between relational features of work - prosocial impact, employee voice and role overload - and job satisfaction and emotional exhaustion and explore whether alienation mediates these relationships. Drawing on data from two public sector organizations in Ireland and the UK $(n=1455)$, our findings show that the relationships between these three work features and job satisfaction are fully mediated by alienation. In the case of emotional exhaustion, our findings indicate that perceptions of the relational elements of prosocial impact and employee voice may give rise to higher levels of exhaustion where employees are alienated. The study's contribution lies in its identification of alienation as an important mechanism through which relational work features influence wellbeing. In addition, by drawing on a relational framework utilised within the engagement literature, the study makes a first attempt in drawing alienation into the wider nomological net proffered by the engagement literature. Thus, it provides new insights into the nature and importance of understanding alienation in contemporary workplaces.
\end{abstract}

Key words: alienation, prosocial impact, employee voice, role overload, job satisfaction, emotional exhaustion, engagement, relational job designs. 


\section{Introduction}

Alienation has a long history within the management literature and yet, until quite recently, had more or less disappeared from the management lexicon. Perhaps its overtones of deprivation, captured through dimensions such as powerlessness, meaninglessness, normlessness, isolation, and self-estrangement (Seeman, 1959), proved too depressing for researchers and managers alike. In addition, from the 1990s onwards attention turned, in the HRM literature in particular, to issues of high performance and its accompanying high commitment and high involvement systems. This generated managerial enthusiasm for research on positive topics with a corresponding 'dominance of consensus-oriented discourse' (Keegan \& Boselie, 2006, p. 1505) in the mainstream HRM journals. More recently, the positive psychology movement, with its emphasis on the affirmative aspects of individuals, groups and organisations, has been influential in both reducing interest into research on negative topics such as alienation (Yousef-Morgan \& Bockorny, 2014) and in increasing interest in studies of positive topics such as engagement. Yet, recent research suggests that alienation is a prevalent feature of contemporary work (Nair \& Vohra, 2010) and that alienated workers experience lower levels of job satisfaction, task performance, and wellbeing, and higher levels of emotional exhaustion and deviance (Chiaburu, Thundiyil, \& Wang, 2014; Shantz et al., 2014; 2015). We contend that an enhanced understanding of this experience is gained by learning more about the processes underpinning and resulting from alienation, defined as 'estrangement or disconnect from work, the context or self' (Nair \& Vohra, 2009, p. 296).

The study makes two contributions. First, we adopt a relational perspective in order to better understand alienation in the contemporary workplace. While both early (e.g. Aiken \& Hage, 1966) and more recent (Nair \& Vohra, 2010) research on alienation suggests that relationships are important in reducing alienating features of work, to our knowledge no research has adopted an explicitly relational approach in the study of alienation. Relational 
mechanisms have been increasingly recognised as salient, yet undervalued, in understanding the nature of the employment relationship (e.g. Grant \& Parker, 2009; Kahn \& Heaphy, 2014).

Our second contribution lies in our contention that a relational framework offers the prospect of bringing together the previously unrelated engagement and alienation literatures. In our exploration of a relational perspective on alienation, we borrow a framework for engagement proposed by Kahn and Heaphy (2014) and consider three relational antecedents: prosocial impact, employee voice and role overload. By drawing on this framework, we develop theory that allows us to position alienation as an important mechanism through which relational work features influence individuals' perceptions of their well-being. We develop the notion of alienation as psychological absence that exhibits physical, cognitive and emotional dimensions (Kahn, 1992) to argue that such dimensions resonate with aspects of physical and psychological well-being, which we capture through job satisfaction and emotional exhaustion. By focusing on both positive and negative outcomes, we differentiate between the 'happiness' and 'health-related' indicators of well-being that have been identified in the wider literature (e.g. Guest, 2017; Van de Voorde, Paauwe, \& Van Veldhoven, 2012). In addition, by drawing alienation into the wider nomological net proffered by the engagement literature, we suggest opportunities for future comparisons that engender a more realistic picture of the world of work. While the concept of alienation has recently been revitalized, its lack of theoretical connection to contemporary constructs leaves it isolated and in danger of disappearing once again. Yet, its relevance is critical given that 'the contemporary workplace is in many ways a much harder and less forgiving place than that of the 1960s and 1970s' (Yuill, 2011, p. 113) when research on alienation flourished. Rather than treating the engagement and alienation literatures as separate and unconnected, our analysis of alienation draws on concepts and constructs found within the broader engagement literature. In particular, we return to Kahn's (1992) seminal work and his exploration of both engagement 
and alienation, thus revisiting a relationship that has been lost in recent analyses of these two constructs.

We structure our paper as follows. We first explore the nature of alienation, its antecedents and outcomes and develop hypotheses for testing. We then describe the two public sector organizations, one in Ireland and one in the UK, in which our study took place. Both organizations had experienced new public management (NPM) reform as well as the impact of the severe economic recession of 2008. We then describe the methodology and results. Finally, we discuss the implications of our findings for both theory and practice.

\section{Understanding alienation}

There are 'complexities and multiple meanings of alienation as a concept' (Yuill, 2011, p. 105). Clark's (1959, p. 849) early definition of alienation viewed it as 'a psychological state of an individual who becomes estranged physically, mentally, or both from aspects of social interactions'. This has been extended into the work context by many writers who view it as a psychological state of estrangement from work (Chiaburu et al., 2014) with connotations of ‘disassociation' (Chiaburu et al., 2014; Nair \& Vohra, 2009; Shantz et al., 2015), 'disconnection' (Nair \& Vohra, 2009; Shantz, Alfes, \& Truss, 2014) and ‘disengagement' (Hirschfeld \& Feild, 2000).

Despite the wealth of research on engagement, and despite a shared focus on the meaning and value of work, the positioning of alienation in relation to contemporary management constructs such as engagement has been explored to only a limited extent (Hirschfeld \& Feild, 2000; Nair \& Vohra, 2012). As a result, the engagement and alienation literatures have for the most part remained separate and unrelated. One notable exception is Kahn's (1990; 1992) work, which adopts a multi-disciplinary and wide-ranging perspective in the exploration of both engagement and disengagement. He proposes personal engagement as 'the simultaneous employment and expression of a person's "preferred self" in task behaviors that promote connections to work and to others, personal presence (physical, cognitive and 
emotional), and active, full-role performances' (p. 700). He views disengagement as the converse of engagement, regarding it as 'the simultaneous withdrawal and defence of a person's preferred self in behaviors that promote a lack of connections, physical, cognitive, and emotional absence, and passive, incomplete role performances', with the removal of 'personal, internal energies from physical, cognitive and emotional labours' (p. 701). The richness and breadth of Kahn's conceptualization of disengagement, and this counterpositioning with engagement, is more comprehensively captured in a later paper (Kahn, 1992). Here Kahn uses the term 'alienation' to explain the lack of a psychological presence of the person-in-role. Kahn draws on the alienation literature to describe this lack of presence as encompassing behaviors such as 'self-estranged' (Seeman, 1959), 'automatic or robotic' (Hochschild, 1983), and 'apathetic or detached' (Goffman, 1961, cited in Kahn, 1992).

In our analysis, we utilize the concept of alienation as a psychological state and investigate its antecedents and outcomes. In so doing it is not our intention to downplay the contributions made by many influential sociologists, philosophers and economists to understanding alienation (see Anthony, 1977 for a review), but rather it reflects the fact that within organizational research alienation has been measured primarily as a psychological construct (Chiaburu et al., 2014). By drawing attention to Kahn's (1992) original conceptualization, we open up the potential for the positioning of alienation within the wider nomological network of engagement, thus providing a more enhanced understanding of the alienation construct in contemporary work contexts.

\section{Antecedents of alienation: A relational perspective}

The meaning that work has for individuals is central to understanding alienation. However, the nature of work has changed dramatically since alienation was first discussed in the management literature, with shifts away from the manufacturing contexts with which alienation was strongly associated. The global shift to knowledge and service economies has 
resulted in changes to the approaches adopted in work design. One new direction is a relational perspective that 'accentuates the roles of interpersonal interactions and interdependencies in work' (Grant \& Parker, 2009, p. 319). Integral to this perspective is the notion of a 'relational architecture' (Grant, 2007), which emphasises the structural properties of work that provide opportunities for such interactions. Kahn and Heaphy (2014) suggest that relational contexts affect the three psychological conditions of meaningfulness, psychological safety and psychological availability. While they apply this framework to understanding engagement, these three psychological conditions also resonate with the elements of meaninglessness, powerlessness and social isolation that have been associated with alienation (Seeman, 1967). We therefore consider each of these antecedents in turn in regard to alienation, focusing on prosocial impact as representing meaningfulness; opportunities for voice as representing psychological safety (powerlessness); and role overload as representing psychological availability (isolation).

\section{Prosocial impact}

Grant (2007) notes that of particular importance to meaningful work is the 'relational architecture of jobs that structures opportunities for employees to have impact on, and form connections with, beneficiaries' (p. 396). Prosocial impact arises when individuals' actions are viewed as beneficial to others, fostering a positive experience for individuals by reducing negativity and emotional exhaustion (Grant, 2007). As Kanfer (2009, p. 122) suggests, 'the products of work motivation and job performance have a relational component ... what employees do at work has import and meaning for others who use the products produced or benefit in some way from the employee's efforts'. This resonates with the view that workers become alienated when they are separated from the product of their labour (Marx, 1844/1969). While no studies have examined prosocial impact as a relational feature of work in the context of alienation, evidence suggests that meaningful work and alienation are negatively related (Mottaz, 1981; Nair \& Vohra, 2010; Shantz et al., 2014). For example, Nair 
and Vohra's (2010) study of knowledge workers highlights the importance of meaningful work, self-expression and quality work relationships in predicting alienation and Shantz et al. (2014) report that meaningful work is negatively related to alienation in a study of manufacturing workers. We extend these studies and propose that employees' perceptions of meaningful work as indicated by the level of prosocial impact they perceive they have on beneficiaries (Grant, 2007; 2008) will negatively influence perceptions of alienation. This is consistent with the view that 'a significant component of peoples' experiences of meaningfulness derives from the relationships they create in the context of their work' (Kahn \& Heaphy, 2014, p. 83). We argue that such relational work and having a prosocial impact on others will negate the feelings of 'disconnection', 'disassociation' and 'disengagement' that have been associated with alienation because it will enhance meaningfulness and because it is valuable to others and to wider society. We hypothesize that:

Hypothesis 1(a): Employee perceptions of prosocial impact will be negatively related to alienation.

\section{Employee voice}

Employee voice has been viewed as 'employees' ability to influence organizational decisions by having the opportunity to advance their ideas and have them considered' (Farndale, Van Ruiten, Kelliher, \& Hope-Hailey, 2011, p. 114), The linkages between power and the ability of employees to voice their views is well established. For example, negative managerial attitudes and behaviour can suppress subordinates' willingness and ability to communicate upwards (Morrison \& Rothman, 2009). In contrast, it is posited that relational environments can be created where there are 'supportive and trusting' interpersonal relationships where individuals can share ideas openly; opportunities for employees to fully participate in their work roles; and 'supportive managerial environments' where people have 'some control over their work' and are able to use 'personal voice' (Kahn \& Heaphy, 2014, pp. 708-713). 
There is evidence that voice initiatives may have positive effects on employees and thus reduce perceptions of alienation. For example, Sarros et al. (2002, p. 298) argue that 'when leaders actively empower employees to contribute to workplace practices and strategic directions, then experiences of work alienation should be rare'. Likewise, in their analysis of employee voice, Shantz et al. (2014) found that employees are less likely to be alienated when they engage in voice behaviors such as making recommendations about, and getting involved in, issues in regard to their work group. Other evidence suggests that employees will be less alienated in work environments where management adopt a more consultative style and offer more involvement in decision making (Sarros et al., 2002). Thus, while certain bureaucratic work environments such as those in the public sector may be associated with constrained work structures (e.g. low levels of autonomy), 'these features can be offset by social relations established in the organisation' (Blyton \& Jenkins, 2007, p. 16). Given these findings, we propose that employee voice, as a relational feature of work, will counteract the feelings of disconnection or estrangement from social interactions that have been associated with alienation (Clark, 1959). This is because such voice will reduce an individual's sense of powerlessness and frustration regarding their work environment (Seeman, 1959) thereby increasing the control they have over the product of their labour or work process (Marx, 1844/1969). We hypothesize that:

Hypothesis 1(b): Employee perceptions of voice opportunities are negatively related to alienation.

\section{Role Overload}

Role overload happens when employees perceive they have too many responsibilities or that expectations are too high given the time available, their abilities, or other pressures (Rizzo, House \& Lirtzman, 1970). Taking a relational perspective, Kahn and Heaphy (2014) suggest that the distractions that people experience in their work can lead them to be unavailable or to retreat and become 'closed off' from others and thus experience the isolation that is embedded 
within understandings of alienation (Seeman, 1959; 1967). It is suggested that public service work has become increasingly pressurized, much more customer-oriented and more open to public scrutiny, with greater accountability and more stringent performance management (Burke, Noblet, \& Cooper, 2013). These pressures intensified during the 2008 economic recession with employee lay-offs, wage, recruitment, and promotion freezes, and increased employees' workloads (Kiefer, Hartley, Conway, \& Briner, 2015). Changes that deplete resources and increase workloads will threaten the level of responsiveness that public sector workers can provide to address citizens' needs and means that employees have fewer personal resources available to dedicate to their in-role performance. This may give rise to considerable disillusionment and will perhaps conflict with the ethos and values that attracted these workers to serve citizens' needs in the first place (Barton Cunningham, 2016), thereby leading to a growing sense of alienation. We therefore hypothesize that:

Hypothesis 1(c): Employee perceptions of role overload will be positively related to alienation.

\section{The outcomes of alienation}

Alienation has been viewed as psychological absence (Kahn, 1992) or disconnection and disillusionment at work (Nair \& Vohra, 2009), which resonates with indicators of physical and psychological well-being (Van de Voorde et al., 2012). We therefore have strong theoretical reasons for proposing a linkage between alienation and well-being. Physical wellbeing relates to employees' health and usually encompasses work stressors and strain that lead to emotional exhaustion (Van De Voorde et al., 2012). Psychological well-being, which encapsulates cognitive and emotional aspects, is often operationalized as employees' level of job satisfaction (Grant, Christianson, \& Price, 2007; Guest, 2017). We theorize about employee-centred well-being outcomes (i.e. job satisfaction and emotional exhaustion) based on psychological absence. We argue that alienated employees will lack the physical, cognitive and emotional energies that may lead to more satisfying work or that may inhibit the 
depletion of resources leading to exhaustion. We examine these two outcomes in the context of public sector work, which has seen increased interaction between public sector workers and the general public in recent years (Kiefer et al., 2015).

Job satisfaction has been defined as 'the pleasurable emotional state resulting from the appraisal of one's job as achieving or facilitating the achievement of one's job values' (Locke, 1969, p. 316). Research shows that, both physically and psychologically, there are reciprocal relationships between job and life satisfaction (Judge \& Watanabe, 1993). Few studies explicitly explore the relationships between alienation and job satisfaction although a recent meta-analysis (Chiaburu et al., 2014) found that alienation was clearly differentiated from, and negatively predicted, job satisfaction. The seminal work by Blauner (1964) on factory workers identified a relationship between alienation and job satisfaction for different types of workers. It is suggested that individuals who are alienated perceive that they lack integration with their work roles, their coworkers, or their organizations (Leiter, 1985) and that this sense of alienation is because their work is not intrinsically rewarding (Seeman, 1971). We propose that alienation will be characterized by a disconnect between individuals' values regarding their selves in role and the pleasure that they derive from their work. We hypothesize that:

Hypothesis 2(a): Alienation will be negatively associated with perceptions of job satisfaction.

Emotional exhaustion is viewed as a core element of burnout and is defined as 'feelings of being emotionally overextended and depleted of one's emotional resources' (Maslach, 1993, pp. 20-21), and impedes individuals from meeting their job demands and fulfilling performance expectations. Marx described the debilitating nature of alienation and suggested that the alienated worker is unable to develop their 'physical and mental powers, but instead becomes physically exhausted and mentally debased' (Marx, 1844/1969, p. 194). In a study of alienation among police officers, Pogrebin (1987) reported an increased sense of alienation 
that resulted in more negative feelings and lethargy. Hochschild (1983) draws on Marx's (1844/1975) work to link alienation to psychological well-being. Her research on the construct of emotional labour suggests that the interactions with the public that are an integral part of new forms of work organization are likely to involve conflict, unpleasant communications and a range of personal costs. Very little recent work has been undertaken on the relationship between alienation and emotional exhaustion with the exception of the work of Shantz et al. (2014) who found that individuals who perceive themselves as alienated from their work are more likely to become emotionally exhausted and experience lower levels of well-being. We expect that the psychological absence that is characterised by alienation will impair individuals' capacities to deal with this disconnection, which will lead to higher emotional exhaustion. We hypothesize that:

Hypothesis 2(b): Alienation will be positively associated with perceptions of emotional exhaustion.

Our final hypotheses concern whether alienation may in fact explain the effects of prosocial impact, employee voice and role overload on job satisfaction and emotional exhaustion. Previous research indicates that prosocial impact and employee voice are related to both job satisfaction (Holland, Pyman, Cooper, \& Teicher, 2011) and emotional exhaustion (Conway et al., 2016; Shantz et al., 2014), while role overload can decrease job satisfaction (Han, Trinkoff, \& Gurses, 2015) and lead to heightened emotional exhaustion (Demerouti, Bakker, Nachreiner, \& Schaufeli, 2001). It has also been suggested that emotional exhaustion manifests from stressful work characterised by high job demands and as a result, employees distance themselves mentally and emotionally from their work (Bakker, Schaufeli, Sixma, Bosveld, \& Van Dierendonck, 2000). It is further suggested that certain work conditions, such as a lack of meaningfulness in work, can lead to alienation which can give rise to lower wellbeing, motivation and performance (Hackman \& Oldham, 1980). We suggest that 
alienated workers will perceive that their work does not fulfill their relational needs which is why they feel alienated and experience negative well-being outcomes. This is also consistent with Marx's (1844/1969) original writings, which suggest that individuals want to engage in activities that promote survival and psychological well-being through connections with others, including connections with the wider society. We propose that perceptions of prosocial impact and employee voice will be linked to higher job satisfaction and lower emotional exhaustion because they will reduce alienation. We suggest that perceptions of role overload will be negatively linked to job satisfaction and positively linked to emotional exhaustion because they may lead to alienation. Thus, we propose that alienation will mediate the relationship between these job features and outcomes and we hypothesize that:

Hypothesis 3: Alienation will mediate the relationships between perceptions of prosocial impact (3a), voice opportunities (3b) and role overload (3c) and job satisfaction.

Hypothesis 4: Alienation will mediate the relationships between perceptions of prosocial impact (4a), voice opportunities (4b) and role overload (4c) and emotional exhaustion.

Figure 1 presents the research model.

(Insert Figure 1 about here)

\section{Methodology}

\section{Participants and procedure}

The data were collected from two organizations, one in the UK and one in Ireland, using an on-line survey that was administered over a two-week period. Initially, information was gathered from senior HR managers in each organization in order to better understand the organizational contexts. They were asked to provide advance notice of the survey and to 
arrange for it to be administered via an email link with a follow-up reminder prior to the close of the survey. In order to control for potential common method bias, the researchers followed established recommendations in the research design (Conway \& Lance 2010; Podsakoff et al., 2012). For example, we provided assurances about the anonymity of the survey and the confidentiality of the data, and prior to distribution we pre-tested the survey among a sample of participants.

In the UK, the data were collected within a large regional police force comprising police officers and staff. Police officers are required to protect the interests and welfare of the public and they may regularly encounter life-threatening situations and deal with violence and other forms of abuse. At the time of the survey, major changes were taking place in the region and the force was required to make significant cost savings while simultaneously undergoing a major transformation involving the restructuring of several departments and the threat of redundancies. Employees were also dealing with the backlash of a decline in spending that gave rise to pay reductions and diminished training and promotion opportunities. In addition, extensive negotiations were taking place to change working hours, to cut shift allowances and to increase the retirement age.

All 1901 employees in the police force were invited to participate in the study and a total of 674 employees completed the survey, yielding a response rate of 35 percent. A number of cases were deleted owing to missing values, which yielded a final sample of 543 . The sample comprised 62 percent of males; the average age was 42 years (s.d. = 8.60); and respondents had worked an average of 18 years in the police force $($ s.d. $=9.36)$.

In Ireland, the data were collected from a large civil service department that provides services such as probation, prisons and immigration with many staff working in complex and demanding public-facing roles. In common with all Irish government departments, it was severely impacted by the 2008 economic crisis that led to major problems with the public finances and a consequent set of measures. These included: public sector pay cuts, a 
moratorium on recruitment and promotion, the introduction of early retirement and career break schemes, a pension-related deduction, reduced pay and pension terms for new entrants, and a reduction in numbers working in the sector. Although such changes were introduced via union agreements, this was not done without major upheaval to individuals' terms and conditions of employment.

All 1955 employees were invited to participate in the study and of these a total of 1017 completed the survey, yielding a response rate of 52 percent. Some cases were deleted owing to missing values, which yielded a final sample of 912. The sample comprised 60 percent of males; the average age was 46 years (s.d. =9.00); and employees had worked on average 21 years in the department (s.d. $=10.40)$.

The combined final sample was 1455, yielding an average overall response rate of 38 percent across the two organizations.

\section{Measures}

The measures were identical across both studies and responses ranged from 1 (strongly disagree) to 5 (strongly agree), unless otherwise noted.

\section{Emotional exhaustion}

We used a shortened three-item version of the Maslach Burnout Inventory (MBI) to measure emotional exhaustion (Maslach \& Jackson, 1981; Hülsheger, Alberts, Feinholdt, \& Lang, 2013). The items were measured on a five-point scale $(1=$ 'never' to $5=$ 'always' $)$ and included statements such as 'I feel emotionally drained from my work'. Cronbach's alpha for the scale was .83 .

\section{Job satisfaction}

We adopted three items developed by Cammann, Fichman, Jenkins, and Klesh (1983) to measure job satisfaction. An example statement was: 'All in all, I am satisfied with my job'. Cronbach's alpha for the scale was .88 .

\section{Alienation}


We used a shortened 3-item measure that was originally developed by Nair and Vohra (2009; 2010) and was later adapted by Shantz et al. $(2014 ; 2015)$. The items were: 'I often wish I were doing something else when I am at work', 'Over the years I have become disillusioned about my work', and 'I do not feel connected to the events in my workplace'. Cronbach's alpha for the scale was .77.

\section{Prosocial impact}

We adapted three items from Spreitzer (1995) and consistent with its theoretical underpinnings, the measure was applied to both external and internal beneficiaries (Grant, 2008) to allow for variation in the degree to which individuals engaged in internal or external customer facing roles. A sample item was: 'I am very conscious of the positive impact that my work has on members of the public and/ or my colleagues'. The reliability of the scale was .88.

\section{Employee voice}

Four items were adopted from Conway et al. (2016). A sample item was: 'Suggestions that I make are taken seriously'. Cronbach's alpha for the scale was .79.

\section{Role overload}

We used the six-item measure adopted by Macky and Boxall (2008). A sample item was: 'I never seem to have enough time to get everything done in my job'. The reliability for the scale was .87 .

\section{Control variables}

We chose our control variables in line with suggestions by Becker $(2005$, p. 285) that there be ‘logical reason, prior evidence or both' for including each one. These were: gender $(0=$ male, $1=$ female), education $(1=$ lower second level to $8=\mathrm{PhD})$, organizational tenure (years), and full-time employment $(1=$ yes; $0=$ no $)$. We distinguished between more or less 'public facing' roles by controlling for officers and non-officers ( $1=$ Officer, $0=$ Non-officer $)$ in the 
UK sample, and department workers and allied agencies $(1=$ Department, $0=$ Agency $)$ in the Irish sample. Finally, we controlled for country $(1=$ Ireland, $0=\mathrm{UK})$.

\title{
Results
}

\section{Descriptive Statistics}

Table 1 presents the means, standard deviations, inter-correlations and reliabilities for all variables.

\author{
(Insert Table 1 about here)
}

\section{Measurement models}

As our data were collected from a single source, we needed to establish whether the variables were distinct before testing our hypotheses and so we carried out a series of confirmatory factor analyses to test for common method bias and to establish the discriminant validity of the scales. A full measurement model was initially tested where all indicators were allowed to load onto their respective factors and all factors were allowed to correlate. The six-factor model showed a good model fit $(\chi 2 / \mathrm{df}=796.93 / 188=4.24, \mathrm{p}<.001, \mathrm{CFI}=.96$, RMSEA $=.05$ and SRMR $=.05)$. Sequential $\chi^{2}$ difference tests were then carried out and the full measurement model was compared to nine alternative nested models as shown in Table 2. The comparison shows that the fit of the alternative models was significantly worse compared to the full measurement model (all at $p<.001$ ).

(Insert Table 2 about here)

We also adopted the CFA marker technique and partialled out an unrelated 'marker variable' (perceived organizational support) as a surrogate for common method in the measurement model. In the original model, squared regression estimates indicated that common variance was about .002 per cent. The CFA marker analysis including POS revealed that common variance remained similar at .001 percept. These results suggest that common method variance is not a concern. 


\section{Test of hypotheses}

We used SEM in Mplus (version 7.4) to test the complete model where all variables were included. The SEM analysis indicated good model fit $(\chi 2 / \mathrm{df}=1364.83 / 302=4.52, \mathrm{p}<.001$, $\mathrm{CFI}=.93, \mathrm{RMSEA}=.05$ and $\mathrm{SRMR}=.06)$. Figure 2 presents the results.

The results provide full support for hypothesis 1 , where prosocial impact $(\beta=-.32, p$ $<.001)$ and voice $(\beta=-.52, \mathrm{p}<.001)$ were both negatively related to alienation, and role overload $(\beta=.13, \mathrm{p}<.001)$ was positively related to alienation. Figure 2 shows that alienation was negatively related to job satisfaction $(-.79, \mathrm{p}<.001)$ and positively related to emotional exhaustion $(\beta=.51, \mathrm{p}<.001)$. This provides support for hypothesis 2 .

(Insert Figure 2 about here)

The support for hypotheses 1 and 2 satisfied the criteria for mediation i.e. that significant relationships exist between the independent variables and the mediator $(\mathrm{H} 1)$ and between the mediator and dependent variables (H2). We used the Mplus syntax developed by Stride, Gardner, Catley, and Thomas (2015) to calculate the indirect effect of the independent variables on the dependent variables via the mediators (hypotheses 3 and 4). Table 3 presents the 99 percent confidence intervals of the bootstrapping results, none of which contain 0 . This provides support for the mediating effect of alienation in the relationship between prosocial impact, employee voice and role overload with job satisfaction and emotional exhaustion.

To further examine the mediated relationships, we checked the direct and indirect effects from our independent variables to dependent variables and the coefficients for both effects are shown in Figure 2. In the case of job satisfaction, the coefficients became nonsignificant when the mediator of alienation was added into the model: prosocial impact (from $\beta=.31, \mathrm{p}<.001$ to $\beta=.05$, n.s.), employee voice (from $\beta=.44, \mathrm{p}<.001$ to $\beta=.03$, n.s.) and role overload (from $\beta=-.12, p<.001$ to $\beta=-.02$, n.s.), suggesting full mediation. However, in the case of emotional exhaustion, the coefficients for prosocial impact (from $\beta=-.08, p$ $<.01$ to $\beta=.08, p<.01$ ) and employee voice (from $\beta=-.18, p<.05$ to $\beta=.08, p<.01$ ) 
became positive and significant, indicating a negative suppressor effect (Tzelgov \& Henik, 1991). The relationship between role overload and emotional exhaustion remained significant when alienation was added to the model (from $\beta=.58, p<.001$ to $\beta=.51, p<.001$ ). Lastly, we adopted Preacher and Kelley's (2011) approach to calculate the effect size of the mediation in order to examine the mediating effect of alienation in the case of employee exhaustion. Results indicated that the mediator (alienation) explained more than a quarter of the total effect $(\kappa 2=.26)$, which is a substantial proportion. Based on the above analysis, as well as the calculated indirect effect and its bootstrapping confidence intervals, we conclude that hypotheses 3 and 4 were supported.

(Insert Table 3 about here)

\section{Discussion}

By utilizing the relational framework proposed by Kahn and Heaphy (2014), we identify the ways in which alienation operates as an important mechanism through which the relational antecedents of prosocial impact, employee voice and role overload impact on individuals' perceptions of their well-being as captured by job satisfaction and emotional exhaustion. We found that where individuals perceive that their roles have a high level of prosocial impact or where they have opportunities for voice, they are more satisfied because these factors decrease levels of alienation. While these results confirm prior literature on the role of meaningful work and employee voice in enhancing job attitudes (Grant, 2007; Nair \& Vohra, 2010; Shantz et al., 2014), they go further in identifying, from a relational perspective, the features of work that can decrease alienation which, in turn, will increase job satisfaction. Our findings also show that perceptions of role overload decrease job satisfaction through increasing alienation. While prior research has shown that alienation negatively predicts job satisfaction (Chiaburu et al., 2014), our focus on the relational factors that can lead to alienation contributes to understanding how it may manifest in organizations. This is an important finding given the pressures experienced by public sector employees in recent years 
(Burke et al., 2013; Kiefer et al., 2015) as it signals, consistent with a social exchange perspective, that employees may become alienated if they perceive that the exchanges in the employment relationship are not reciprocal (Blau, 1964).

In regard to emotional exhaustion as another indicator of well-being, our findings are in line with studies that have shown a positive relationship between alienation and emotional exhaustion (Shantz et al., 2014). However, the negative coefficients of both prosocial impact and voice became positive when alienation was added into the model, suggesting the presence of a suppressor effect. This resonates with May et al.'s (2004) research where a similar effect arose between resources, availability and engagement and we interpret our finding likewise. We suggest that the effect may be because (a) alienation is more strongly correlated with emotional exhaustion compared to either prosocial impact and voice and that (b) the inclusion of alienation in the model seems to suppress irrelevant variance that is shared with exhaustion. Thus, the indirect effect suggests that alienation changes the relationship between both prosocial impact and voice with emotional exhaustion and that exhaustion levels increase alongside increased prosocial impact and voice when alienation is added to the model. These findings highlight the importance of moving beyond a focus on direct effects alone, which may 'mask' more valid interpretations of tricky findings. This is important because, as Rucker, Preacher, Tormala and Petty (2011, p. 368) point out, suppressor effects 'provide an opportunity to acquire a deeper understanding of the relationships among variables' and that 'a theory that takes into account mediating and suppressing variables is more complete than a theory that examines only the former'.

Given the consistency in our findings regarding prosocial impact and voice, it appears that in situations where employees are alienated, additional opportunities for increased prosocial impact or voice may simply put extra burdens on employees, thereby converting such interactions into stressors that act as hindrances rather than challenges (Cavanaugh, Boswell, Roehling, \& Boudreau, 2000). We found that individuals in client-facing roles were 
significantly more exhausted than those in other types of roles. This is in line with evidence that the interactions with service recipients that lies at the heart of prosocial work can place high emotional demands on employees, particularly where recipients are demanding or abusive (Grandey \& Diamond, 2010). Overall, these findings point to the negative well-being outcomes that may be encountered where employees try to enact all their roles.

In regard to the relationship between role overload and emotional exhaustion, the link is partially mediated by alienation. Thus, individuals who perceive they are experiencing high workloads are more exhausted, but perceptions of alienation only partially explain the relationship. This indicates that there may be other mediators that explain the relationship between role overload and emotional exhaustion, perhaps related to personal resources (e.g. resilience, coping ability) or other relational resources (e.g. supportive management and coworkers).

In addition to the overall findings, we also found a number of other differences in our sample. Our findings show that levels of emotional exhaustion were higher among the UK sample suggesting that the stressful nature of police work, including dealing with emergencies, confrontation and sometimes violence, takes a higher emotional toll on these workers. Our findings also show that levels of alienation were higher among the Irish sample perhaps due to a heightened sense of powerlessness and less meaningful work arising from the range of austerity measures undertaken. In addition, we found that those with higher levels of education were less satisfied perhaps due to diminishing promotion opportunities and the concomitant lack of opportunity to utilise their skills. Our analysis underlines the relevance of alienation in understanding both the meaning of work for individuals and aspects of their well-being and provides rich insights into how alienation manifests and how it can be managed. In particular, we explored alienation in a public sector context, one that has not been explored in recent alienation studies. Our choice 
of a relational framework was in line with our aim to situate alienation within a contemporary work setting and to revitalise its relevance as an important construct in understanding the meaning and value of work within present-day studies of HRM. Although the notion of alienation has recently been revitalised (Nair \& Vohra, 2012; Shantz et al., 2014; 2015), its lack of theoretical connection to contemporary constructs means that there is the danger that it may become isolated and disappear once again. We argue that a relational framework also offers the prospect of drawing alienation into a wider nomological net proffered by the engagement literature. While empirical research has yet to establish its value in this regard, such a framework offers the opportunity to posit a relationship between alienation and engagement that has disappeared since Kahn's (1992) brief exposition linking both constructs. Rather than seeing the engagement and alienation literatures as separate and unrelated, a relational perspective provides the opportunity for future comparisons between them. Such comparisons would engender a more realistic picture of the world of work by highlighting both positive and negative aspects, rather than the one-sided, positive perspective that has emerged in many engagement studies (Purcell, 2014).

\section{Implications for practice}

In their focus on a relational framework, the findings have implications for the ways in which HR managers might tackle issues regarding employee alienation and well-being in a public sector context. First, in regard to prosocial impact, job redesign initiatives such as providing greater feedback regarding the prosocial difference that individuals make through their work, will provide for more meaningful work thus enabling individuals to build their skill-sets in order to acquire the competencies required for higher-level positions, as well as ensuring that work is more varied and interesting and affords contact with a wider range of people. HR managers may need to consider carefully the trade-offs between the potentially beneficial managerial outcomes of any new initiatives against their possible negative impacts on employee well-being by taking into account its physical, psychological and social dimensions, 
as well as the level of complexity in job roles. Second, in regard to voice, the findings suggest that initiatives aimed at providing workers with greater voice in decision making about their own work, such as suggestion schemes and the provision of information on what is happening in the organisation, are important in reducing alienation and enhancing job satisfaction. Third, in regard to role overload, there needs to be adequate supports to cope with complex and challenging work demands coupled with a balance between the other relational work features in order to reduce levels of alienation. Finally, the encouragement of a positive social and physical environment with the promotion of health and safety, equal opportunities and family friendly initiatives, as well as attention to problematic issues such as harassment and bullying, are critical if employees are to feel that that there is fair exchange and a mutually respectful employment relationship. This can be achieved through a focus on 'relational leadership' (Stephens \& Carmeli, 2017) in which leaders promote a sense of dignity and worth among employees, which will enhance both meaning and purpose in their work roles.

\section{Limitations and future research}

While the research provides a number of new and important insights, some limitations should be noted. First, due to the study's cross-sectional nature and its reliance on self-report measures, the possibility of common method bias cannot be completely ruled out. While our analysis suggests that such bias is not a serious concern, we cannot draw firm conclusions in the absence of longitudinal data. Second, while we might have included more objective assessments of the constructs used in our study, we regard these as not readily observable by others due to their subjective and personal nature. Third, given the neglected focus on alienation in the literature, there are numerous other potential influences, including dispositional characteristics, which future research should consider. Fourth, the consistency in our findings suggests that the relationships detected may be generalizable, at least in public sector settings. It would, however, be beneficial to explore these relationships across a wider 
range of sectors and international contexts as a further test of their generalizability. Finally, we believe that positioning alienation within a relational framework allows for a more enhanced understanding of both alienation and engagement, but future research needs to explore this positioning in more detail.

\section{Conclusion}

Our research provides a counterbalance to the emphasis on positive psychology within recent HRM scholarship in its exploration of the processes underpinning and resulting from alienation. As such, it highlights a darker and frequently neglected side to the experiences of workers in employment as well as providing an important and fruitful avenue for future research.

\section{References}

Aiken, M., \& Hage, J. (1966). Organizational alienation: A comparative analysis. American Sociological Review, 31, 497-507.

Anthony, P.D. (1977). The ideology of work. London: Tavistock.

Bakker, A.B., Schaufeli, W.B., Sixma, H., Bosveld, W., \& Dierendonck, D. (2000). Patient demands, lack of reciprocity, and burnout: A five-year longitudinal study among general practitioners. Journal of Organizational Behavior, 21, 425-441.

Barton Cunningham, J. (2016). Strategic human resource management in the public arena: A managerial perspective. London: Palgrave MacMillan.

Becker, T. E. (2005). Potential problems in the statistical control of variables in organizational research: A qualitative analysis with recommendations. Organizational Research Methods, 8, 274-289.

Blau, P.M. (1964). Exchange \& Power in Social Life. New Brunswick, NJ: Transaction.

Blauner, R. (1964). Alienation and Freedom: The Factory Worker and His Industry. Chicago: Chicago University Press. 
Blyton, P., \& Jenkins, J. (2007). Alienation. In P. Blyton \& J. Jenkins, Key concepts in work (pp. 11-16). London: Sage Publications.

Burke, R.J., Noblet, A.J., \& Cooper, C.L. (Eds) (2013). Human resource management in the public sector. Cheltenham: Edward Elgar Publishing.

Cammann, C., Fichman, M., Jenkins, G.D., \& Klesh, J.R. (1983). Assessing the attitudes and perceptions of organizational members. In S.E. Seashore, E.E. Lawler, P.H. Mirvis, \& C. Cammann (Eds.), Assessing Organizational Change (pp. 71-138). New York: John Wiley and Sons.

Cavanaugh, M. A., Boswell, W. R., Roehling, M. V., \& Boudreau, John W. (2000). An empirical examination of self-reported work stress among US managers. Journal of Applied Psychology, 85, 65-74.

Chiaburu, D., Thundiyil, T., \& Wang, J. (2014). Alienation and its correlates: A metaanalysis. European Management Journal, 32, 24-36.

Clark, J.P. (1959). Measuring alienation within a social system. American Sociological Review, 24, 849-852.

Conway, J. M., \& Lance, C. E. (2010). What reviewers should expect from authors regarding common method bias in organizational research. Journal of Business and Psychology, 25, $325-334$.

Conway, E., Monks, K., Fu, N., Alfes, K., \& Bailey, C. (2016). Demands or resources? The relationship between HR practices, employee engagement, and emotional exhaustion within a hybrid model of employment relations. Human Resource Management. 55, 901917.

Demerouti, E., Bakker, A.B., Nachreiner, F., \& Schaufeli, W.B. (2001). The job demandsresources model of burnout. Journal of Applied Psychology, 86, 499-512. 
Farndale, E., Van Ruiten, J., Kelliher, C., \& Hope-Hailey, V. (2011). The influence of perceived voice on organizational commitment: An exchange perspective. Human Resource Management, 50, 113-129.

Goffman, E. (1961). Encounters: Two studies in the sociology of interaction. Indianapolis: Bobbs-Merrill Co.

Grandey, A., \& Diamond, J. (2010). Interactions with the public: Bridging job design and emotional labor perspectives. Journal of Organizational Behavior, 31, 338-50.

Grant, A.M. (2007). Relational job design and the motivation to make a prosocial difference. Academy of Management Review, 32, 393- 417.

Grant, A.M. (2008). The significance of task significance: Job performance effects, relational mechanisms, and boundary conditions. Journal of Applied Psychology, 93, 108 -24.

Grant, A.M., Christianson, M.K., \& Price, R.H. (2007). Happiness, health, or relationships? Managerial practices and employee well-being tradeoffs. Academy of Management Perspectives, 21, 51-63.

Grant, A.M., \& Parker, S.K. (2009). Redesigning work design theories: The rise of relational and proactive perspectives. The Academy of Management Annals, 3, 317-375.

Guest, D.E. (2017). Human resource management and employee well-being: Towards a new analytical framework. Human Resource Management Journal, 27, 22-38.

Hackman, J. R., \& Oldham, G. R. (1980). Work redesign. Reading MA: Addison-Wesley.

Han, K., Trinkoff, A.M., \& Gurses, A.P. (2015). Work-related factors, job satisfaction and intent to leave the current job among United States nurses. Journal of Clinical Nursing, 24, $3224-3232$.

Hirschfeld, R.R., \& Feild, H.S. (2000). Work centrality and work alienation: Distinct aspects of a general commitment to work. Journal of Organizational Behavior, 21, 789-800.

Hochschild, A.R. (1983). The managed heart. Berkeley: University of California Press. 
Holland, P., Pyman, A., Cooper, B.K., \& Teicher, J. (2011). Employee voice and job satisfaction in Australia: The centrality of direct voice. Human Resource Management, 50, 95-111.

Hülsheger, U., Alberts, H., Feinholdt, A., \& Lang, J. (2013). Benefits of mindfulness at work: The role of mindfulness in emotion regulation, emotional exhaustion and job satisfaction. Journal of Applied Psychology, 98, 310-325.

Judge, T., \& Watanabe, S. (1993). Another look at the job satisfaction-life satisfaction relationship. Journal of Applied Psychology, 78, 939-948.

Kanfer, R. (2009). Work motivation: Advancing theory and impact. Industrial and Organizational Psychology, 2, 118-127.

Kahn, W. (1990). Psychological conditions of personal engagement and disengagement at work. Academy of Management Journal, 33, 692-724.

Kahn, W. (1992). To be fully there: Psychological presence at work. Human Relations, 45, $321-349$

Kahn, W., \& Heaphy, E. (2014). Relational contexts of personal engagement at work. In C. Truss, R. Delbridge, K. Alfes, A. Shantz, \& E. Soane (Eds.), Employee engagement in theory and practice (pp. 82-96). London: Routledge.

Keegan, A., \& Boselie, P. (2006). The lack of impact of dissensus inspired analysis on developments in the field of human resource management. Journal of Management Studies, 43, 1491-1511. 
Kiefer, T., Hartley, J. Conway, N., \& Briner, R.B. (2015). Feeling the squeeze: Public employees' experiences of cutback and innovation-related organizational changes following a national announcement of budget reductions. Journal of Public Administration Research and Theory, 25, 1279-1305.

Leiter, J. 1985. Work alienation in the textile industry: Reassessing Blauner. Work and Occupations, 12, 479-498.

Locke, E. A. (1969). What is job satisfaction? Organizational Behavior and Human Performance, 4, 309-336.

Macky, K., \& Boxall, P. (2008). High-involvement work processes, work intensification and employee well-being: A study of New Zealand worker experiences. Asia Pacific Journal of Human Resources, 46, 38-55.

Marx, K. (1844/1969). Alienated Labour, Edited by P. Gardener, New York: Free Press.

Marx, K. (1844/1975). Economic and philosophic manuscripts of 1844. In Vol. 3: Collected Works, 229-346. London: Penguin.

Maslach, C., \& Jackson, S.E. (1981). The measurement of experienced burnout. Journal of Occupational Behavior, 2, 99-113.

Maslach, C. (1993). Burnout: A multidimensional perspective. In: W. Schaufeli, C. Maslach, and T. Marek (Eds.), Professional burnout: Recent developments in theory and research (pp. 19-32). Washington, DC: Taylor \& Francis.

May, D.R., Gilson, R.L., \& Harter, L.M. (2004). The psychological conditions of meaningfulness, safety and availability and the engagement of the human spirit at work. Journal of Occupational and Organizational Psychology, 77, 11-37.

Morrison, E.W., \& Rothman, N.B. (2009). Silence and the dynamics of power. In J.

Greenberg, \& M.S. Edwards (Eds). Voice and silence in organizations. London: Emerald. Mottaz, C.J. (1981). Some determinants of work alienation. The Sociological Quarterly, 22, 515-29. 
Nair, N., \& Vohra, N. (2009). Developing a new measure of work alienation. Journal of Workplace Rights, 14, 293-309.

Nair, N., \& Vohra, N. (2010). An exploration of factors predicting work alienation of knowledge workers. Management Decision, 48, 600-15.

Nair, N., \& Vohra, N. (2012). The concept of alienation: towards conceptual clarity. International Journal of Organizational Analysis, 20, 25-50.

Podsakoff, P. M., MacKenzie, S. B., \& Podsakoff, N. P. (2012). Sources of method bias in social science research and recommendations on how to control it. Annual Review of Psychology, 63, 539-569.

Pogrebin, M. (1987). Alienation among veteran police officers. The Police Chief, February, $38-42$.

Preacher, K.J., \& Kelley, K. (2011). Effect size measures for mediation models: Quantitative strategies for communicating indirect effects. Psychological Methods, 16, 93-115.

Purcell, J. (2014). Employee voice and engagement. In C. Truss, R. Delbridge, K. Alfes, A. Shantz, \& E. Soane (Eds.), Employee engagement in theory and practice (pp. 236-250). London: Routledge.

Reddy, S.K. (1992). Effects of ignoring correlated measurement errors in structural equation models. Educational and Psychological Measurement, 52, 549-90.

Rizzo, J., House, R., \& Lirtzman, S. (1970). Role conflict and ambiguity in complex organizations. Administrative Science Quarterly, 15, 150-163.

Rucker, D.D., Preacher, K.J., Tormala, Z.L., \& Petty, R.E. (2011). Mediation analysis in social psychology: Current practices and new recommendations. Social and Personality Psychology Compass, 5/6, 359-371.

Sarros, J.C., Tanewski, G.A., Winter, R.P., Santora, J.C., \& Densten, I.L. (2002). Work alienation and organizational leadership. British Journal of Management, 13, 285-304. 
Seeman, M. (1959). On the meaning of alienation. American Sociological Review, 24, 783791.

Seeman, M. (1967). Powerlessness and knowledge: A comparative study of alienation and learning. Sociometry, 30, 105-123.

Seeman, M. (1971). Alienation: A map. Psychology Today, 5, 83-84.

Shantz, A., Alfes, K., \& Truss, C. (2014). Alienation from work: Marxist ideologies and 21st century practice. The International Journal of Human Resource Management, 25, 2529-50.

Shantz, A., Alfes, K., Bailey, C., \& Soane, E. (2015). Drivers and outcomes of work alienation: Reviving a concept. Journal of Management Inquiry, 24, 382-93.

Spreitzer, G.M. (1995). Psychological empowerment in the workplace: Dimensions, measurement, and validation. Academy of Management Journal, 38, 1442-65.

Stephens, J.P., \& Carmeli, A. (2017). Relational leadership and creativity: The effects of respectful engagement and caring on meaningfulness and creative work involvement. In S. Hemlin \& M. D. Mumford (Eds.), Handbook of Research on Creativity and Leadership. Cheltenham: Edward Elgar Publishing.

Stride, C.B., Gardner S., Catley. N., \& Thomas, F. (2015). Mplus code for mediation, moderation, and moderated mediation models. Retrieved on February 17, 2017, from http://www.offbeat.group.shef.ac.uk/FIO/mplusmedmod.htm.

Tzelgov, J., \& Henik, A. (1991). Suppression situations in psychological research: Definitions, implications and applications. Psychological Bulletin, 109, 524-536.

Van De Voorde, K., Paauwe, J., \& Van Veldhoven, M. (2012). Employee well-being and the HRM-organizational performance relationship: A review of quantitative studies. International Journal of Management Reviews, 14, 391-407. 
Youssef-Morgan C., \& Bockorny, K. (2013). Engagement in the context of positive psychology. In C. Truss, K. Alfes, R. Delbridge, A. Shantz, \& E. Soane (Eds) Employee engagement in theory and practice (pp. 36-56). London: Routledge.

Yuill, C. (2011). Forgetting and remembering alienation theory. History of the Human Sciences, 24, 103-119. 
Table 1. Descriptive statistics

\begin{tabular}{|c|c|c|c|c|c|c|c|c|c|c|c|c|c|}
\hline & & Mean & $\mathrm{SD}$ & 1 & 2 & 3 & 4 & 5 & 6 & 7 & 9 & 10 & 11 \\
\hline 1 & Job satisfaction & 3.60 & .90 & & & & & & & & & & \\
\hline 2 & Emotional exhaustion & 2.95 & .81 & $-.30^{* *}$ & & & & & & & & & \\
\hline 3 & Alienation & 2.68 & .89 & $-.71^{* *}$ & $.37^{* *}$ & & & & & & & & \\
\hline 4 & Prosocial impact & 3.91 & .83 & $.40^{* *}$ & $-.06^{*}$ & $-.41^{* *}$ & & & & & & & \\
\hline 5 & Employee voice & 2.79 & .85 & $.47^{* *}$ & $-.21^{* *}$ & $*-.49^{* *}$ & $.25^{* *}$ & & & & & & \\
\hline 6 & Role overload & 3.04 & .84 & $-.20^{* *}$ & $.52^{* *}$ & $.17^{* *}$ & .02 & $-.16^{* *}$ & & & & & \\
\hline 7 & Gender & .53 & .50 & .00 & -.02 & .00 & -.02 & $-.07^{*}$ & .03 & & & & \\
\hline 8 & Education & 4.30 & 1.29 & $-.06^{*}$ & -.04 & .01 & .00 & $-.06^{*}$ & $.13^{* *}$ & .03 & & & \\
\hline 9 & Full-time & .86 & .34 & -.01 & .05 & -.01 & .04 & -.01 & .03 & $-.28^{* *}$ & $.11^{* *}$ & & \\
\hline & Tenure & 19.65 & 10.17 & .02 & -.02 & -.04 & $.06^{*}$ & .05 & $.10^{* *}$ & .01 & $-.07^{*}-.10^{* *}$ & & \\
\hline & 1 Country & .68 & .47 & $-.13^{* *}$ & $-.15^{* *}$ & ${ }^{*} .15^{* *}$ & $-.19^{* *}$ & $-.14^{* *}$ & .00 & $.22^{* *}$ & $.39^{* *}-.04$ & $.14^{* *}$ & \\
\hline & 2 Job type (client facing role) & .70 & .46 & -.01 & .04 & .05 & $-.09^{* *}$ & -.01 & -.02 & $-.06^{*}$ & $.08^{* *} .09^{* *}$ & .06 & $.18^{* *}$ \\
\hline
\end{tabular}

Note: $\mathrm{N}=1455$ (listwise). ${ }^{* *} \mathrm{p}<.01,{ }^{*} \mathrm{p}<.05$ (two tailed) 
Table 2. Fit statistics from measurement model comparison

\begin{tabular}{|c|c|c|c|c|c|c|}
\hline Models & $\chi^{2}(d f)$ & $C F I$ & RMSEA & $S R M R$ & $\Delta \chi^{2}$ & $\Delta d f$ \\
\hline Full measurement model & 796.93(188) & .96 & .05 & .05 & & \\
\hline Model $\mathrm{A}^{\mathrm{a}}$ & $1567.36(193)$ & .91 & .07 & .11 & 770.43 & $5 * * *$ \\
\hline Model B ${ }^{b}$ & $3433.83(193)$ & .80 & .11 & .16 & 1636.90 & $5 * * *$ \\
\hline Model C ${ }^{c}$ & 4199.68(197) & .76 & .12 & .18 & 3402.75 & $9 * * *$ \\
\hline Model $\mathrm{D}^{\mathrm{d}}$ & $2278.93(193)$ & .87 & .09 & .09 & 1481.99 & $5 * * *$ \\
\hline Model E $\mathrm{e}^{\mathrm{e}}$ & $2727.14(193)$ & .85 & .10 & .08 & 1930.21 & $5 * * *$ \\
\hline Model Ff & $1853.78(193)$ & .90 & .08 & .07 & 1056.85 & $5 * * *$ \\
\hline Model G ${ }^{\mathrm{g}}$ & $3034.66(193)$ & .83 & .10 & .14 & 2237.73 & $5 * * *$ \\
\hline Model $\mathrm{H}^{\mathrm{h}}$ & $1136.45(193)$ & .94 & .06 & .06 & 339.52 & $5 * * *$ \\
\hline Model I ${ }^{\mathrm{i}}$ & $6926.89(203)$ & .59 & .15 & .15 & 796.93 & $15 * * *$ \\
\hline
\end{tabular}

Notes: ${ }^{* *} \mathrm{p}<.001 ; \chi^{2}=$ chi-square discrepancy, $\mathrm{df}=$ degrees of freedom; IFI = Incremental Fit Index; CFI = Comparative Fit Index; RMSEA = Root Mean Square Error of Approximation; SRMR = Standardised Root Mean Square Residual; $\Delta \chi^{2} \chi_{\text {diff }}^{2}=$ difference in chi-square, $\Delta d f d f_{\text {diff }}=$ difference in degrees of freedom. In all measurement models, error terms were free to covary between one pair of pro-change behavior items to improve fit and help reduce bias in the estimated parameter values (Reddy, 1992). All models were compared to the full measurement model.

$a=$ Prosocial impact and voice combined into a single factor

$\mathrm{b}=$ Prosocial impact and role overload combined into a single factor

${ }^{c}=$ Prosocial impact, voice and role overload into a single factor

$\mathrm{d}=$ Alienation and exhaustion combined into a single factor

$\mathrm{e}=$ Prosocial impact and job satisfaction combined into a single factor

$\mathrm{f}=$ Role overload and exhaustion combined into a single factor

$\mathrm{g}=$ Role overload and alienation combined into a single factor

$\mathrm{h}=$ Voice and job satisfaction combined into a single factor

$\mathrm{i}=$ All factors combined into a single factor 
Table 3. Indirect Effect and Bootstrapping test results (99\% CIs)

\begin{tabular}{ccc}
\hline & Job satisfaction & Emotional exhaustion \\
\hline Prosocial impact & $.293^{* * *}[.202, .384]$ & $-.167^{* * *}[-.229,-.105]$ \\
Employee voice & $.448^{* * *}[.327, .570]$ & $-.256^{* * *}[-.346,-.165]$ \\
Role overload & $-.103^{* * *}[-.168, .039]$ & $.059^{* * *}[.022, .096]$ \\
\hline
\end{tabular}

Note: $* * * p<.001$ 


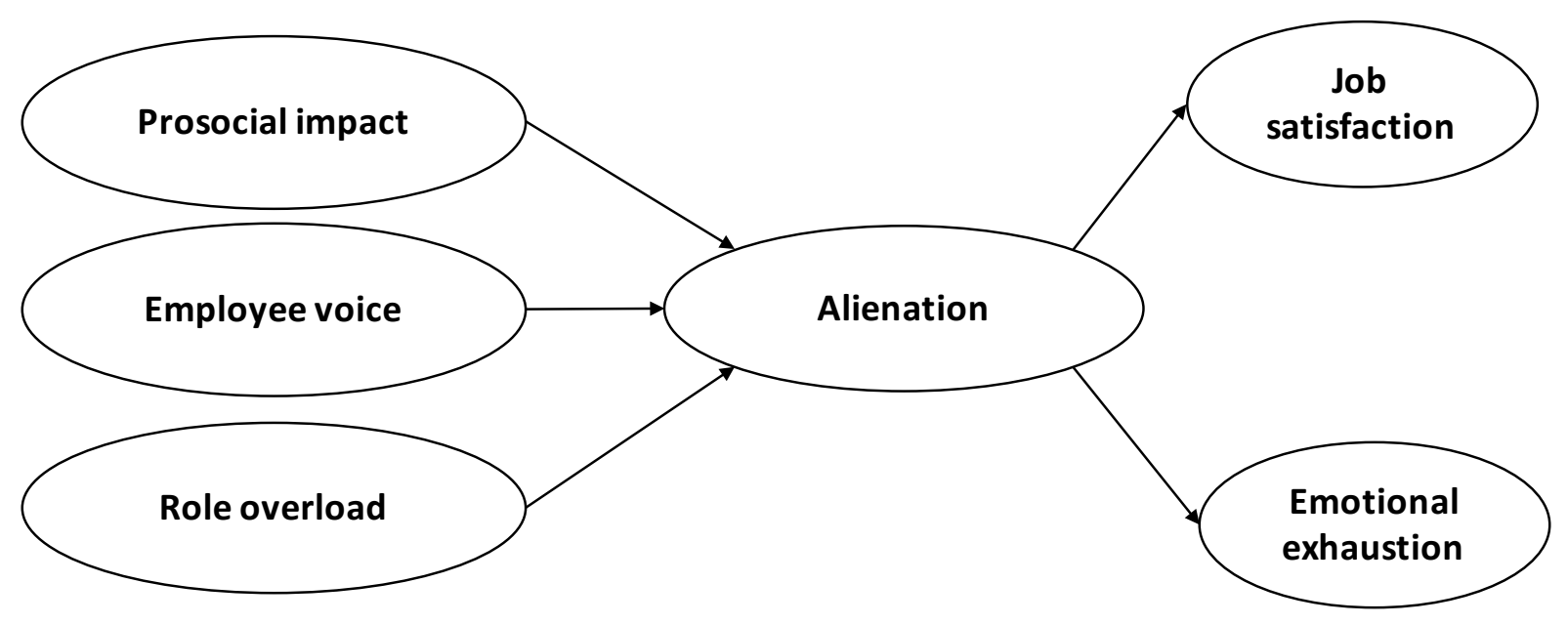

Figure 1. Conceptual Model

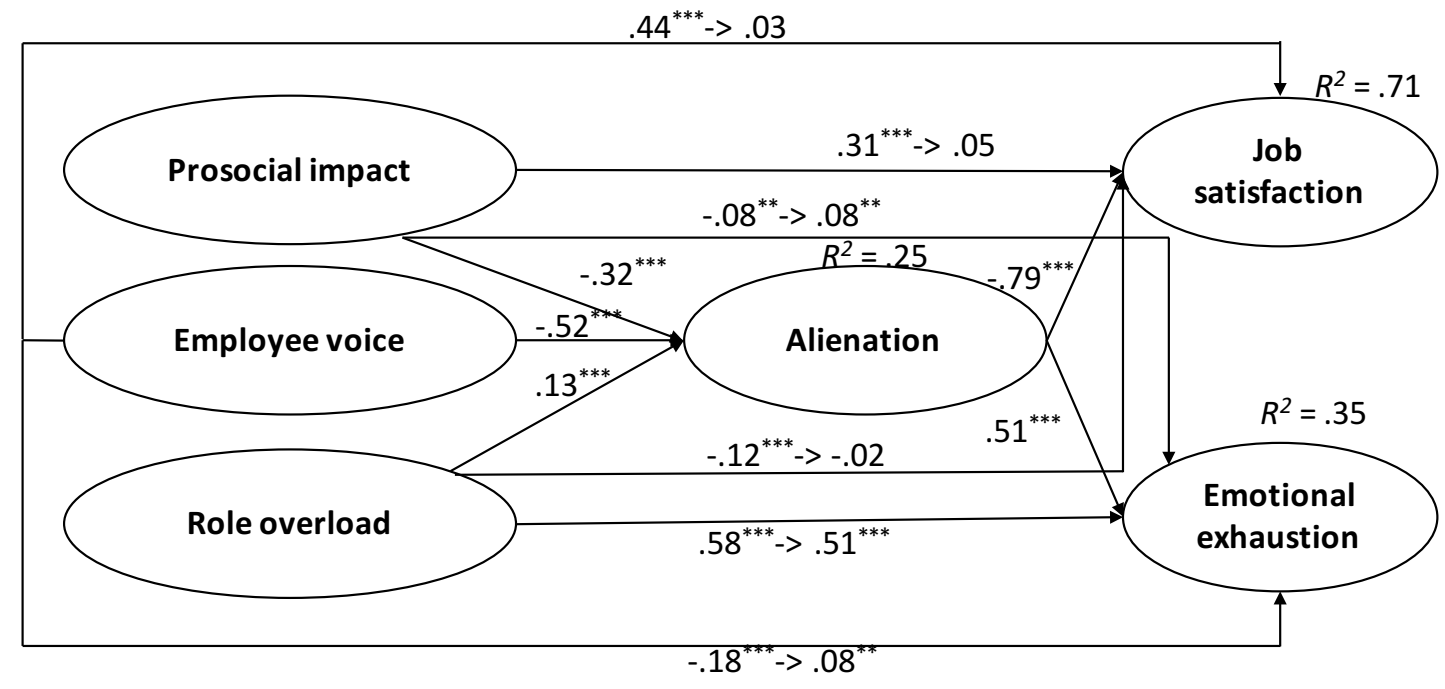

\begin{tabular}{lccc} 
Control variables & Alienation & Job satisfaction & Emotional exhaustion \\
\hline Gender & .02 & -.02 & .03 \\
Education & -.05 & $-.07^{* *}$ & -.04 \\
Fulltime & .00 & -.01 & .03 \\
Tenure & -.01 & -.01 & -.04 \\
Country & $.06^{*}$ & .02 & $-.22^{* * *}$ \\
Job type (client-facing) & .02 & .04 & $.08^{* *}$
\end{tabular}

Note: Standardized coefficients were reported. $\mathrm{N}=1239$ (listwise). ${ }^{* * *} \mathrm{p}<.001,{ }^{* *} \mathrm{p}<.01,{ }^{*} \mathrm{p}<.05$ (two tailed).

Figure 2. SEM Results 